\title{
Prediction of reservoir performance in multi-well systems using modified hyperbolic model
}

\author{
Y. B. Adeboye $\cdot$ C. E. Ubani $\cdot$ O. Oribayo
}

Received: 29 March 2011/Accepted: 13 August 2011/Published online: 15 September 2011

(C) The Author(s) 2011. This article is published with open access at Springerlink.com

\begin{abstract}
Decline curve analyses are usually based on empirical Arps' equations: exponential, hyperbolic and harmonic decline. The applicable decline for the purpose of reservoir estimates is usually based on the historical trend that is seen on the well or reservoir performance. This remains an important tool for the reservoir engineer, so that the practice of decline curve analysis has been developed over the years through both theoretical and empirical considerations. Despite the fact that the fundamental principles are well known and understood, there are aspects which can still lead to a range of forecast and reserve estimates that until now have not been investigated. In this work, a model was developed considering the effect of well aggregation and interference in multi-well systems. This approach accounts for the entire production history of the well and the reservoir, and thus reduces the influence of well interference effects on decline curve analysis. It provides much better estimates of reserves in multi-well systems. The models were validated with field data from different wells. Production decline data from different wells in a reservoir were analyzed and used to demonstrate the application of the developed model.
\end{abstract}

Y. B. Adeboye $(\bowtie)$

Department of Petroleum and Gas Engineering, University of Lagos, Akoka, Yaba, Lagos, Nigeria

e-mail: yadeboye@unilag.edu.ng

C. E. Ubani

Department of Petroleum and Gas Engineering, University of Port-Harcourt, Port-Harcourt, Nigeria

O. Oribayo

Department of Chemical Engineering,

University of Lagos, Akoka, Yaba, Lagos, Nigeria
Keywords Decline curve - Well aggregation Interference $\cdot$ Forecast $\cdot$ Reserve estimates

$\begin{array}{ll}\text { List of symbols } \\ N_{\mathrm{P}} & \text { Production (liter) } \\ q_{i} & \text { Initial oil production rate (liter/year) } \\ b & \text { Constant } \\ D_{i} & \text { Constant } \\ q & \text { Oil production rate (liter/year) } \\ t & \text { Production time } \\ N_{\mathrm{Px}} & \text { Cumulative oil production (liter) } \\ q_{\mathrm{x}} & \text { Cumulative oil production rate (liter/year) } \\ t_{\mathrm{x}} & \text { Cumulative production time (year) } \\ \text { DCA } & \text { Decline curve analysis }\end{array}$

\section{Introduction}

Production of hydrocarbons declines due to a decline in reservoir energy and/or increases in producing water cut. Graphical plots of performance data provide a time-tested, frequently used technique known as "decline curve" for estimating ultimate recovery and/or reserves to be expected from a well, reservoir or field.

Decline curve analysis is used for analyzing declining production rates and forecasting future performance of oil and gas wells. Forecasting future production is essential in economic analysis of exploration and production expenditures. Hence, the analysis of production decline curves represents a useful tool for forecasting future production from wells and reservoirs. The basis of this procedure is that factors which have affected production in the past will continue to do so in future.

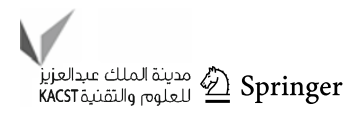


Most conventional decline curve analyses are based on the classic works of Arps (1970) and Fetkovich (1980), which illustrate the analysis of well performance data using empirically derived exponential, harmonic and hyperbolic functions. Although the study of Arps (1970) is completely empirical, its simplicity and the fact that it requires no knowledge of reservoir or well parameters make its use widespread in the upstream petroleum industry, particularly for production prediction and estimating reserves from production decline behavior. However, our observation is that the Arps' method completely ignores the flowing pressure data, does not account for changing production conditions and changing gas properties with time (reservoir pressure); thus, it yields inconsistent results (unreliable matches and poor extrapolation).

Regarding the research works of Fetkovich (1980) and Fetkovich et al. (1998), we noticed that their works discuss the use of Arps' hyperbolic relations and that they do provide a semi-analytical result for gas flow behavior which, unfortunately, is never valid in practice. To address the impact of pressure-dependent gas properties on the evaluation of gas production data, Fraim and Watten Barger (1987) presented a decline type curve for gas reservoir systems. Although the Fraim and Watten Barger (1987) approach is more rigorous than simply using the hyperbolic model, the Fraim solution is not universal. The decline type curves not only permit forecast of well performance, but also estimate reservoir properties (i.e., flow capacity in $k h$ ) as well as oil in place.

The Fetkovich method was improved upon by the introduction of two additional type curves, which were plotted concurrently with the normalized rate type curves: the rate integral function and derivative function, which help in smoothing the often noisy character of production data and in obtaining a more unique match (Blasingame et al. 1991). The Blasingame et al. (1991) method is similar to that of Fetkovich in that they use type curves for production data analysis. However, the primary difference is that the modern method incorporates the flowing pressure data along with production rates and use analytical solutions to calculate hydrocarbons in place.

McCray (1990) developed a time function that would transform production data for systems exhibiting variable rate or pressure drop performance into an equivalent system produced at a constant bottom-hole pressure, which was extended by Blasingame et al. (1991) to an equivalent "constant rate" analysis approach. The issue of variable, non-constant bottom-hole pressures in gas wells was addressed by Palacio and Blasingame (1993). They introduced new methods, which use a modified time function for analyzing the performance of single phase liquid or gas wells. One of the shortcomings of this method is that it completely ignores the flowing pressure data; thus, when applied, there is always underestimation or overestimation of reserves. Besides, it does not account for changing production conditions and thus cannot always provide a reliable estimate of recoverable hydrocarbons in place, and changing gas properties with time (reservoir pressure) are not accounted for; thus, gas reserves are usually underestimated.

Fetkovich et al. (1998) was the first to apply the concept of using type-curves to transient production. The research methodology of Fetkovich (1980) and Fetkovich et al. (1998) was the same as that of Arps (1970) depletion for the analysis of boundary-dominated flow and constant pressure type curves originally developed by Van Everdingen and Hurst for transient production. Type-curve matching is essentially a graphical technique for visual matching of production data using pre-plotted curves on a $\log -\log$ paper. The most valuable feature of type curves lies not in the analysis, but in the diagnostics. Fetkovich et al. (1998) presented the theoretical basis for Arps' production decline models using the pseudo-steady state flow equation. The decline type curves not only permit forecast of well performance, but also estimate reservoir properties (i.e., flow capacity in $k h$ ) as well as oil in place.

The Fetkovich method was improved upon by the introduction of two additional type curves, which were plotted concurrently with the normalized rate type curves that help in smoothing the often noisy character of production data and in obtaining a more unique match (Blasingame et al. 1989). McCray TL (1990) developed a time function that would transform production data for systems exhibiting variable rate or pressure drop performance into an equivalent system produced at a constant bottom-hole pressure, which was extended by Blasingame et al. (1991) to an equivalent "constant rate" analysis approach.

The issue of variable, non-constant bottom-hole pressures in gas wells was addressed by Palacio and Blasingame (1993). They introduced a new method which uses a modified time function for analyzing the performance of single phase liquid or gas wells. The method of Blasingame et al. (1991) is similar to that of Fetkovich in that they use type curves for production data analysis. However, the primary difference is that the modern method incorporates the flowing pressure data along with production rates and use analytical solutions to calculate hydrocarbons in place.

Rodriguez and Cinco-Ley (1993) developed a model for production decline in a bounded multi-well system. The primary assumptions in their model are that the pseudosteady state flow condition exists at all points in the reservoir and that all wells produce at a constant bottom-hole pressure. They concluded that the production performance of the reservoir was shown to be exponential in all cases, as long as the bottom-hole pressures in individual wells were maintained constant. Camacho et al. (1996) improved the 
Rodriguez-Cinco-Ley model by allowing individual wells to produce at different times.

Valko et al. (2000) presented a "multi-well productivity index" concept for an arbitrary number of wells in a bounded reservoir system. $\mathrm{Li}$ and Home (2005) and Guo et al. (2007) proposed semi-analytical, direct solutions for determining average reservoir pressure, rate and cumulative production for gas wells produced at a constant bottom-hole flowing pressure. These authors also assumed the existence of pseudo-steady state flow, but proved that the concept was valid for constant rate, constant pressure or variable-rate/variable pressure production.

Despite the wide use of decline curve analysis and typecurve matching of oil well, they sometimes over-predict or underestimate reserves. The subjectivity of other methods along with the need for pressure data necessitates the development of our model, which does not require pressure data and also eliminates the subjectivity of the analysis.

The specific objectives of this paper are to:

- develop a model to estimate reserve and predict reservoir performance for multi-well reservoir system using production data analysis;

- demonstrate the applicability of the newly developed model by validating it with existing models and field data.

\section{Model development}

The new model is a modification of that used by Arps.

The basic assumptions are:

1. Whatever causes controlled the trend of a curve in the past will continue to govern its trend in the future in a uniform manner.

2. According to Fetkovich, if production from each well in a reservoir or field followed the exponential decline solution, the total decline curve analysis production from the reservoir or field would be better estimated using hyperbolic decline model.

A hyperbolic decline occurs when the decline rate is no longer constant. Compared to exponential decline, the following two hyperbolic decline curve equations estimate a longer production life of the well.

For hyperbolic decline

$N_{\mathrm{P}}=\frac{q_{i}^{b}}{(b-1) D_{i}}\left\{\left(q^{1-b}-q_{i}^{1-b}\right)\right\}$

and $q=\frac{q_{i}}{\left(1+b D_{i} t\right)^{\frac{1}{b}}}$

Combining Eq. 2.1 with 2.2 yields the expression given as

$N_{\mathrm{P}}=\frac{q_{i}^{b}}{(b-1) D_{i}}\left\{\left(\frac{q_{i}}{\left(1+b D_{i} t\right)^{\frac{1}{b}}}\right)^{1-b}-q_{i}^{1-b}\right\}$

Further simplification of Eq. 2.3 yields the equations:

$N_{\mathrm{P}}=\frac{q_{i}^{b}}{(b-1) D_{i}}\left\{\left(q_{i}\right)^{1-b}\left(\left(1+b D_{i} t\right)^{\frac{b-1}{b}}-1\right)\right\}$

$\left.N_{\mathrm{P}}=\frac{q_{i}}{(b-1) D_{i}}\left\{\left[\left(1+b D_{i} t\right)\left(1+b D_{i} t\right)^{\frac{-1}{b}}\right]-1\right)\right\}$

$N_{\mathrm{P}}=\frac{q_{i}}{(b-1) D_{i}}\left\{\left(1+b D_{i} t\right)\left(\frac{q}{q_{i}}-1\right)\right\}$

$N_{\mathrm{P}}=\frac{1}{(b-1) D_{i}}\left\{\left(1+b D_{i} t\right)\left(q-q_{i}\right)\right\}$

$N_{\mathrm{P}}=\frac{1}{(b-1) D_{i}}\left\{\left(q+q b D_{i} t-q_{i}\right)\right\}$

$N_{\mathrm{P}}(b-1) D_{i}=\left\{\left(q+q b D_{i} t-q_{i}\right)\right\}$

$N_{\mathrm{P}}(b-1) D_{i}+q_{i}=q\left\{1+b D_{i} t\right\}$

$q-\frac{N_{\mathrm{P}}(b-1) D_{i}+q_{i}}{\left\{1+b D_{i} t\right\}}$

Equation 2.11 is derived from the hyperbolic solution, but can be used for both the exponential and harmonic solution; thus, the developed equation is a general equation.

When cumulative production $\left(N_{p}\right)$ is expressed in terms of the previous cumulative production $\left(N_{p x}\right)$ and production rate $q$ over a period of time, the equation obtained is given as

$N_{\mathrm{p}}=N_{\mathrm{Px}}+q\left(t-t_{\mathrm{x}}\right)$

Substituting for $N_{p}$ in Eq. 2.11 gives

$q-\frac{\left(N_{\mathrm{Px}}+q\left(t-t_{\mathrm{x}}\right)\right)(b-1) D_{i}+q_{i}}{\left\{1+b D_{i} t\right\}}$

$q\left\{1+b D_{i} t\right\}=\left(N_{\mathrm{Px}}+q\left(t-t_{\mathrm{x}}\right)\right)(b-1) D_{i}+q_{i}$

$q\left\{1+b D_{i} t\right\}=N_{\mathrm{Px}}(b-1) D_{i}+q\left(t-t_{\mathrm{x}}\right)(b-1) D_{i}+q_{i}$

$q\left\{1+b D_{i} t\right\}-q\left(t-t_{\mathrm{x}}\right)(b-1) D_{i}=N_{\mathrm{Px}}(b-1) D_{i}+q_{i}$

$q\left\{\left(1+b D_{i} t\right)-\left[\left(t-t_{\mathrm{x}}\right)(b-1) D_{i}\right]\right\}=N_{\mathrm{Px}}(b-1) D_{i}+q_{i}$ 
Rearranging Eq. 2.17 yields

$$
q=\frac{N_{\mathrm{Px}}(b-1) D_{i}+q_{i}}{\left\{\left(1+b D_{i} t\right)-\left[\left(t-t_{\mathrm{x}}\right)(b-1) D_{i}\right]\right\}}
$$

By simplifying the denominator and if $t-t_{x} \approx t$, then

$q=\frac{q_{i}+N_{\mathrm{Px}}(b-1) D_{i}}{1+t D_{i}}$

In the case of forecast or prediction of reservoir performance for a multi-well system, Eq. 2.19 can be used, but $D_{i}$ is replaced by $D_{t}$

Then Eq. 2.19 is the modified hyperbolic model that can be used to calculate the future production rate based on the initial production rate $q_{t}$, previous cumulative production $N_{p x}$, and constants $D_{t}$ and b for a multi-well reservoir system. The procedure for determining model parameters, i.e., $D_{i^{-}}$and $b$-values is the same as that in the hyperbolic model and is shown in Appendix A

\section{Model validation}

In this study, the basic principle/fundamental concept used is that of Arps' model; hence, result from the developed model is validated with Arps' exponential and hyperbolic model using the production data from reservoirs (A and B) given below as case study.

\section{Reservoir A: case study}

This reservoir is an integrated oil and gas reservoir with major oil reserves with two wells drilled through it and still producing up to date. The off-take built up rapidly from 2001 and reached a peak of 4852.64 stb/d by August 2001. Subsequently, off-take has shown natural decline from the wells. The predominant drive mechanism is both the aquifer and gravity; hence the values of $b$ ranging from $0.5-0.8$ will be acceptable for DCA. There is currently pressure maintenance and artificial lift scheme in this reservoir due to the high viscosity of the oil. In this multi-well reservoir, the producing drainage points do not display any visible decline trend that can be useful for DCA; thus it is recommended to carry out the DCA first on reservoir basis, and then on the drainage points with established trends. Due to the interconnectivity test carried out, it was discovered that there was possibility of interference between these wells; hence reservoir is suitable for use as case study.

\section{Reservoir B: case study}

This is an oil reservoir with little gas reserves. It has three wells drilled through it and two are still producing to the present. The off-take built up rapidly from 1974 and reached a peak of $6763.88 \mathrm{stb} / \mathrm{d}$ by April 1994. Subsequently, the off-take has shown a natural decline, with beaning down of the wells. The predominant drive mechanism is aquifer. The well that has quit production is due to depletion of reservoir energy. There is currently neither pressure maintenance nor artificial lift in this reservoir. Presently, there is poor production allocation in terms of well performance, hence reservoir $\mathrm{B}$ is a suitable multiwell reservoir system for case study.

\section{Data analysis}

The production data from reservoir A and B were analyzed using conventional Arps' exponential and hyperbolic decline models, juxtaposing the results obtained to validate the developed model. The production curves shown in Figs. 1, 2, and 3 were plotted using each of the model for reservoirs A and B, respectively. From each plot, the model parameters shown in Tables 1 and 2 for exponential, hyperbolic and developed models were determined using the procedure shown in Appendix A. Having substituted the obtained parameters shown in Tables 1 and 2 in

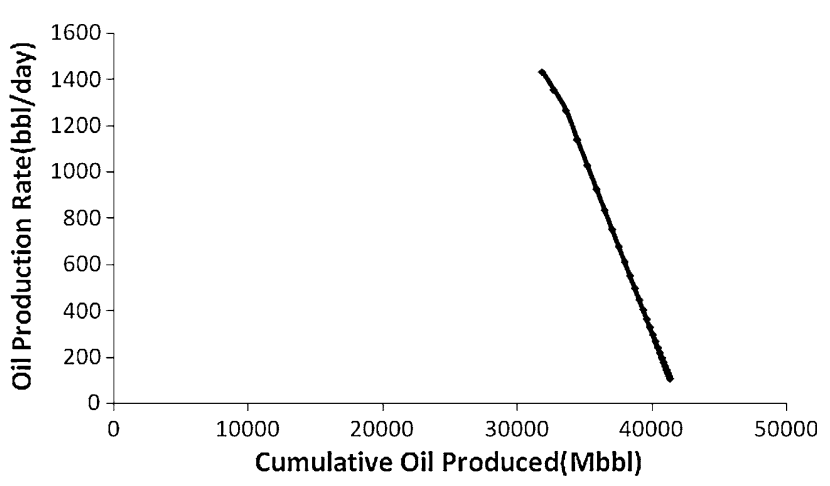

Fig. 1 Exponential decline production plot for reservoir A

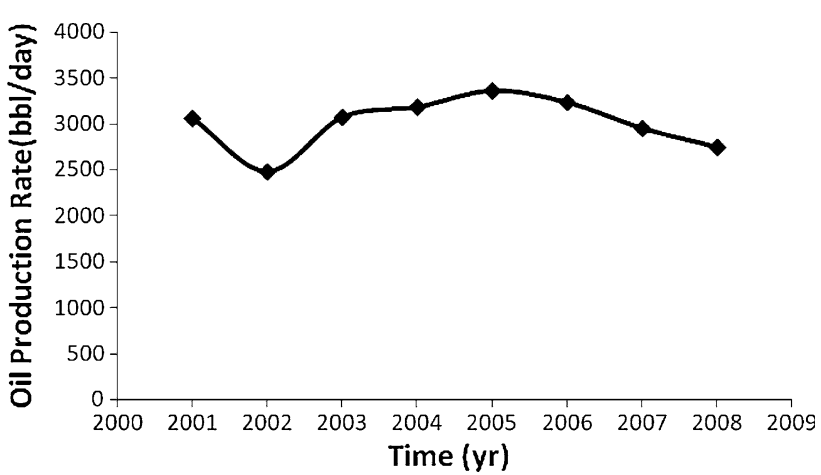

Fig. 2 Hyperbolic decline production plot for reservoir A 


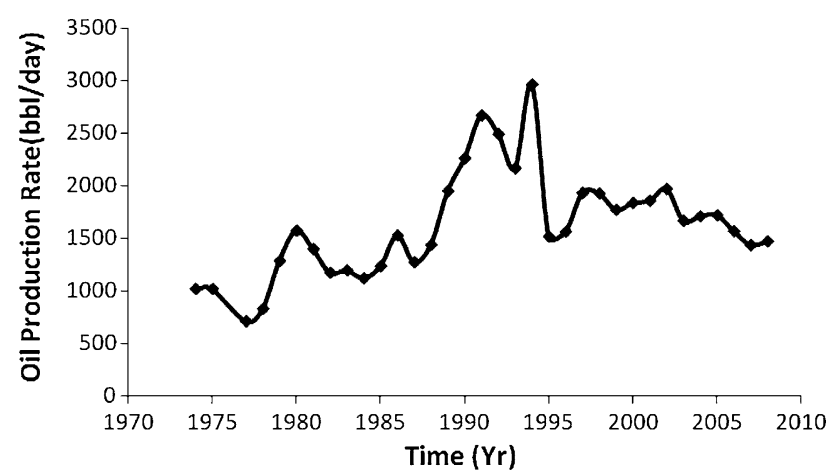

Fig. 3 Hyperbolic decline production plot for reservoir B

Table 1 Model parameters

\begin{tabular}{lll}
\hline $\begin{array}{l}\text { Parameters obtained } \\
\text { from graph }\end{array}$ & $\begin{array}{l}\text { For multi-well } \\
\text { reservoir system A }\end{array}$ & $\begin{array}{l}\text { For multi-well } \\
\text { reservoir system B }\end{array}$ \\
\hline Slope & -0.668 & -0.302 \\
$\begin{array}{l}\text { Nominal decline factor } \\
D_{i}(/ \text { year) }\end{array}$ & -0.2438 & -0.1102 \\
Effective decline factor $(d)$ & 0.21637 & 0.10437 \\
\hline
\end{tabular}

Table 2 Model parameters

\begin{tabular}{lll}
\hline $\begin{array}{l}\text { Parameters obtained } \\
\text { from graph }\end{array}$ & $\begin{array}{l}\text { For multi-well } \\
\text { reservoir system } \\
\mathrm{A}\end{array}$ & $\begin{array}{l}\text { For multi-well } \\
\text { reservoir system } \\
\mathrm{B}\end{array}$ \\
\hline $\begin{array}{l}\text { Hyperbolic exponent }(b) \\
\text { Nominal decline factor }\end{array}$ & 0.765 & 0.945 \\
$D_{i}$ (/year) & 0.07024 & 0.0484 \\
$\begin{array}{l}\text { Decline rate factor, } D_{t} \text { (/year) } \\
\text { Decline rate factor, } D_{t} \text { (/year) }\end{array}$ & 0.06667 & 0.000183 \\
\hline
\end{tabular}

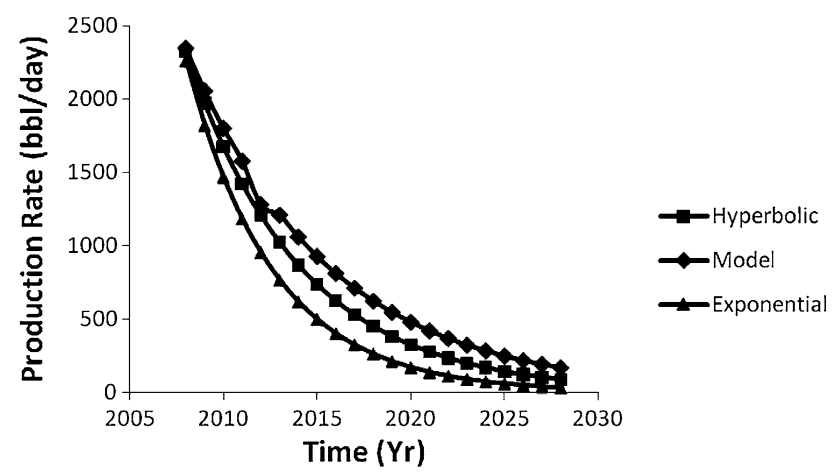

Fig. 4 Production rate decline comparison of the three models

exponential, hyperbolic and developed models, the production rate decline curves shown in Figs. 4, 56 and 7 were obtained.

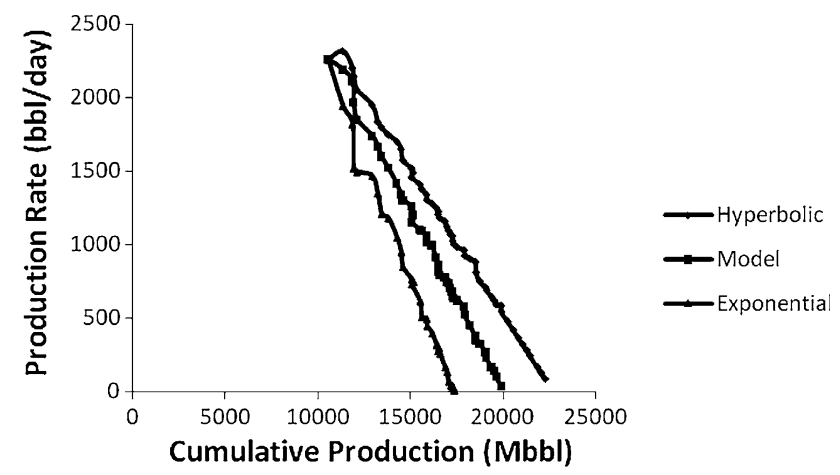

Fig. 5 Production comparison of the three models

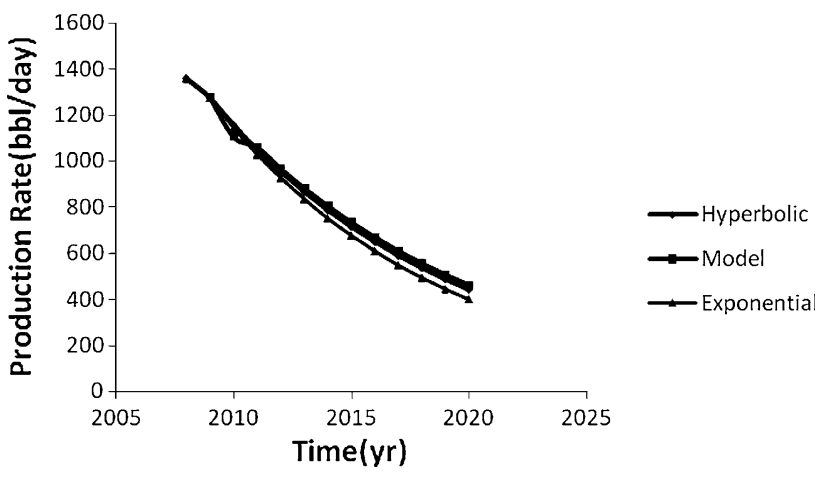

Fig. 6 Production rate decline comparison of the three models

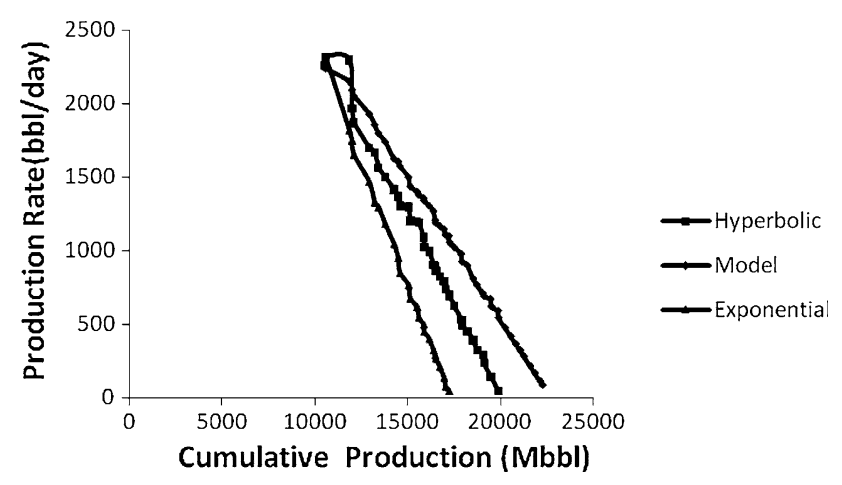

Fig. 7 Production comparison of the three models

\section{Results and discussions}

The basic principle/fundamental concept used is that of Arps' model; hence, results from the developed model are compared with those of Arps' exponential and hyperbolic model. The comparison demonstrated in Fig. 4, 5, 6 and 7 reveals that the exponential model tends to underestimate reserves and production rates, while the hyperbolic model over-predicts the reservoir performance. The accurate prediction, using the developed model, is achieved due to the fact that: the use of cumulative production rate in the 
new model takes into cognizance the effect of well interference (volumetric mass influx) by new wells, which steal from other wells. The pressure data are not used in this case. Also, the adverse effects of downtime experienced using a model that only relates the rate and time are reduced, because 'gaps' in the production data during periods of no production disappear when cumulative production is integrated in the developed modified hyperbolic model.

The consequence of underestimating or over-predicting reserves is that it will affect the investment decisions. This is because production forecasts, together with product prices, operating costs and investments, are used to determine the project economics. Revenue is then predicted when pricing forecasts are combined with the volumes forecast. Production forecast data are also used to develop expense forecasts. These forecasts are made on the basis of production volumes and the forecasts of active completions and related operational considerations. In turn, profit can be predicted based on expected revenue and expenses. Profit predictions will be used for work planning and project justification.

However, the forecasts have direct dollar impacts far beyond an organization. Based upon these forecasts, a company can supply and coordinate marine and pipeline transportation resources required to get the oil and gas to market. On the other hand, forecasting too low may lead to purchase of expensive spot capacity to handle the extra production. In the longer term, forecasts affect more strategic decisions such as whether a producing property should be kept or sold, the long-term availability of capital for new projects, and whether a company should adjust its pipeline or marine transportation capacity.

\section{Conclusion}

Based on the present study, the following conclusions may be drawn in the cases studied:

1. The limitations of the Arps' hyperbolic decline model have been corrected by taking into cognizance the effect of well aggregation and interference in multiwell systems using high level reservoir data.

2. The comparison of model predictions using the reservoir production data demonstrated that the developed modified hyperbolic model had the best prediction compared to the exponential and the harmonic models in the cases studied.

3. The study also revealed that decline analysis and reserve estimation based on decline analysis must be carried out with good understanding of the factors that control the decline.
Open Access This article is distributed under the terms of the Creative Commons Attribution License which permits any use, distribution and reproduction in any medium, provided the original author(s) and source are credited.

Appendix A: Determination of the hyperbolic exponent, initial nominal and effective decline constant for hyperbolic decline as stated in the economic analysis and investment decision by Ikoku (1985), University of Port Harcout, Nigeria

This is a curve-fitting procedure based on reading three points from a smooth curve representing a set of data points in the most direct method of analyzing hyperbolic decline curves. The procedure is as follows

For multi-well system A

From Fig. 2,

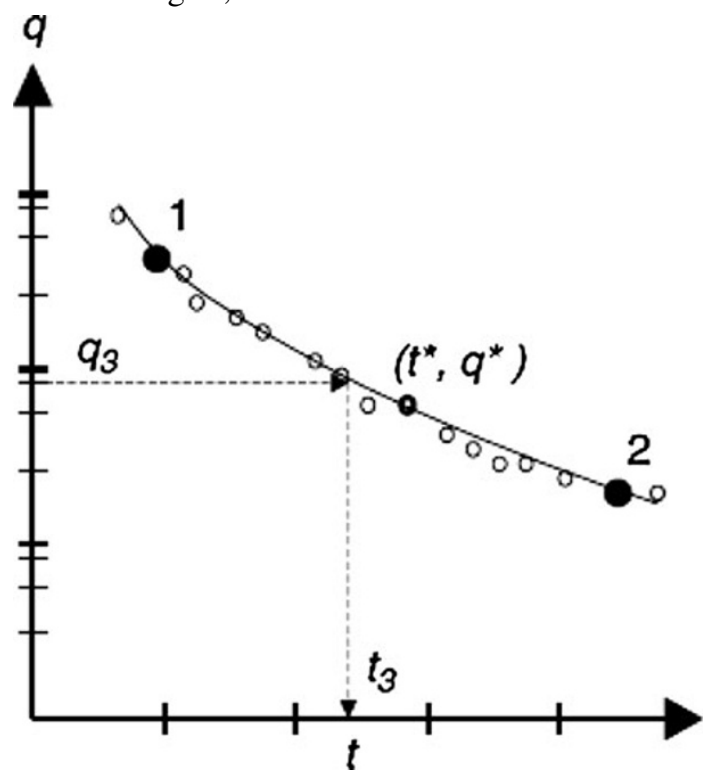

a. Select points $\left(t_{1}, q_{1}\right)$ and $\left(t_{2}, q_{2}\right)$

$t_{1}=1$ year, $q_{1}=4475 \mathrm{bbl} /$ day

$t_{2}=7$ years, $q_{2}=2750 \mathrm{bbl} /$ day

b. $\quad \operatorname{Read} t_{3}$ at $q_{3}=\sqrt{q_{1} q_{2}}$ $q_{3}=\sqrt{4475 \times 2750}=3508 t_{3}=3.8$ years

c. Calculate $\left(\frac{D i}{d}\right)=\frac{t_{1}+t_{2}-2 t_{3}}{t_{3}^{2}-t_{1} t_{2}}=0.0537$

d. Find $q_{0}$ at $t=0, q_{0}=4800 \mathrm{bbl} /$ day

e. Pick up any point $\left(t^{*}, q^{*}\right)$ say $t^{*}=2$ years, $q^{*}=4200 \mathrm{bbl} / \mathrm{day}$

f. $\quad q^{*}=\frac{q_{o}}{\left(1+\left(\frac{D i}{d}\right) t^{*}\right)} \Rightarrow d=\frac{\log \left(\frac{q_{o}}{q^{*}}\right)}{\log \left(1+\left(\frac{D i}{d}\right) t^{*}\right)}=1.308$

g. Finally, $D_{i}=\left(\frac{D_{i}}{d}\right) d$

h. $(0.0537 \times 1.308)=0.07024 /$ year

where $d=1 / b, b=0.765$.

The hyperbolic decline constant at some future time, $t$, is defined by the following equation $D_{t}$ : 
$D_{t}=\frac{D_{i}}{1+b D_{i} t}$

Therefore,

$D_{t}=\frac{0.07024}{1+(0.765 \times 0.07024 \times 1)}$

$D_{t}=0.06667 /$ year

$D_{t}=\frac{0.06667}{\text { year }} \times \frac{1 \text { year }}{365 \text { days }}=0.000183 /$ day

\section{Appendix B: Illustrating the applicability of the modified hyperbolic model using a case study}

It is required to forecast the production rate of a reservoir in 2 years' time using DCA by Arps' model and the modified Arps' model. The analysis is to be carried out at the end of 2008 after the well had produced 9 MMstb. The analysis of the production data gave a nominal exponential decline rate of $0.11023 \mathrm{pa}$ and an estimate for the initial rate for the forecast of $1374.17 \mathrm{stb} /$ day and the hyperbolic exponent of 0.945 with an initial nominal decline rate of $0.0463 /$ year.

This can easily be done because the equations are not of a complex form. Using Arps' model:

For the exponential DCA,

$q=q_{1} \mathrm{e}^{-D t}$

Therefore,

$q=1374.17 \mathrm{e}^{-0.11023 \times 2}$

$q=1102.29 \mathrm{bbl} / \mathrm{day}$

For the Arps' hyperbolic DCA,

$q=\frac{q_{t}}{\left(1+b D_{t} t\right)^{\frac{1}{b}}}$

Therefore,

$q=1374.17(1+(0.945 \times 0.0463 \times 2))^{-\frac{1}{0.945}}$

$q=1257.44 \mathrm{bbl} / \mathrm{day}$.

Using the modified hyperbolic model given by

$q=\frac{q_{i}+N_{\mathrm{Px}}(b-1) D_{i}}{1+t D_{i}}$

$q=\frac{\left[1374.17+\left\{9 \times 10^{6} \times(0.945-1) \times 0.0463 \times\left(\frac{1}{365}\right)\right\}\right]}{1+(2 \times 0.0463)}$ $q=1200.24 \mathrm{bbl} / \mathrm{day}$.

This illustrated that when the multi-well system production forecast is done using the three models, the exponential model underestimates the reservoir performance while the hyperbolic overestimates the reservoir performance, but the modified hyperbolic model gives a better result that is higher than the value of the exponential but lower than that of the hyperbolic model. This is because the modified model makes use of the entire cumulative oil production data of wells in the multi-well system, and hence gives a better result.

\section{References}

Arps, JJ (1970) Oil and gas property evaluation and reserve estimates, vol. 3, Reprint Series, SPE, Richardson, TX, pp 93-102

Blasingame TA, Etherington JR, Hunt EJ, Adewusi A (1989) Decline Curve Analysis Using Type-Curves. SPE 110927

Blasingame TA, McCray, TC, Lee, WJ (1991) Decline curve analysis for variable pressure drop/variable flowrate system. SPE 21513

Camacho VR, Rodriguez, F, Galindo-NA, Prats M (1996) Optimum position for wells producing at constant wellbore pressure. SPE, vol 1, pp 155-168

Fetkovich, MJ (1980) Decline curve analysis using type curves. JPT, 1065-1077

Fetkovich MJ et al (1998) Decline curve analysis using type-curves. SPE 13169

Fraim ML, Watten Barger RA (1987) Gas reservoir decline analysis using type curves with real gas pseudo-pressure and normalized time. SPEFE (Dec. 1987)620

Guo B, Lyons WC, Ghalambor A (2007) Petroleum production engineering - a computer-assisted approach. Elsevier Science \& Technology Books Publishers, Amsterdam, pp 98-105

Ikoku CU (1985) The economic analysis and investment decision, 3rd edn. University of Port Harcourt, Nigeria

Li K, Home RN (2005) Verification of decline curve analysis models for production prediction. SPE 93878

McCray, TL (1990) Reservoir analysis using production decline data and adjusted time. MS Thesis, Texas A \& M University College Station, TX

Palacio JC, Blasingame TA (1993) Decline curve analysis using type curves. SPE 25909

Rodriguez F, Cinco-Ley H (1993) A new model for production decline. SPE 25480

Valko PP, Doublet, LE, Blasingame TA (2000) Development and application of the multiwell productivity index (MPI). SPEJ 